\title{
Assessment of the radiative effects of aerosols in an on-line coupled model over the Iberian Peninsula: Supplementary Material
}

Laura Palacios-Peña ${ }^{1}$, Rocío Baró ${ }^{1}$, Juan L. Guerrero-Rascado ${ }^{2,3}$, Lucas Alados-Arboledas ${ }^{2,3}$, Dominik Brunner ${ }^{4}$, Pedro Jiménez-Guerrero* ${ }^{1}$

5 'Department of Physics, Regional Campus of International Excellence "Campus Mare Nostrum", Campus de Espinardo, University of Murcia, Murcia, 30100, Spain

${ }^{2}$ Andalusian Institute for Earth System Research (IISTA-CEAMA), Av. del Mediterráneo, Granada, 18006, Spain

${ }^{3}$ Department Applied Physics, University of Granada, Fuentenueva s/n, Granada, 18006, Spain

${ }^{4}$ Laboratory for Air Pollution/Environmental Technology (EMPA), Swiss Federal Laboratories for Materials Science and

10 Technology, Dübendorf, 8600 Switzerland

*Correspondence to: Pedro Jiménez-Guerrero (pedro.jimenezguerrero@um.es) 


\section{AOD $_{550}$ Aqua-MODIS (Dust Episode)}

\section{Observed value}

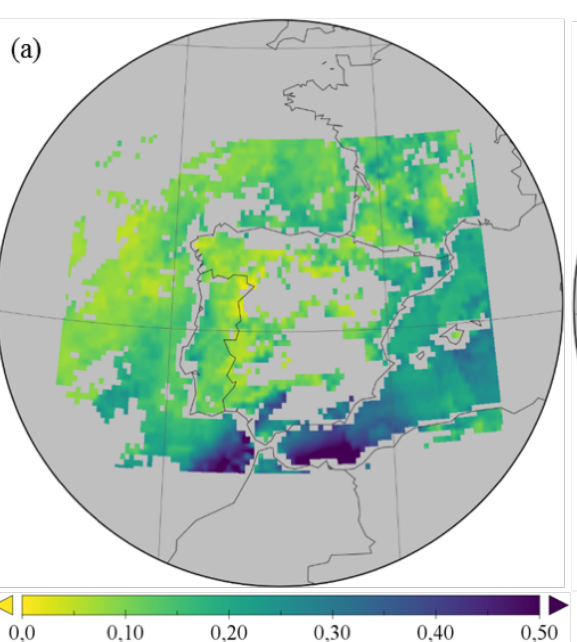

Improvement of MAE

(b)

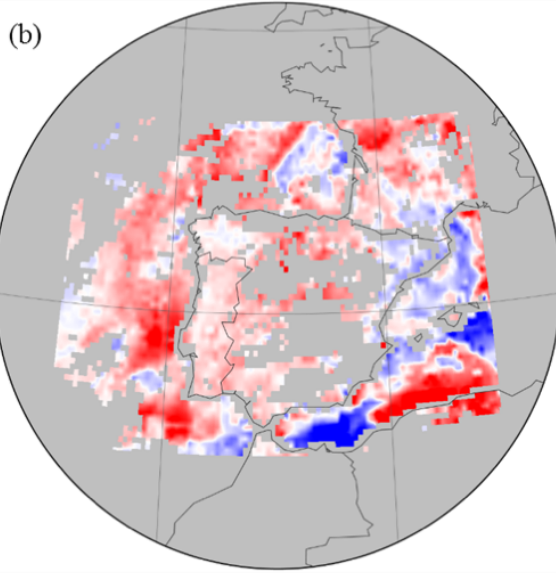

Mean Bias Error

$N R F$

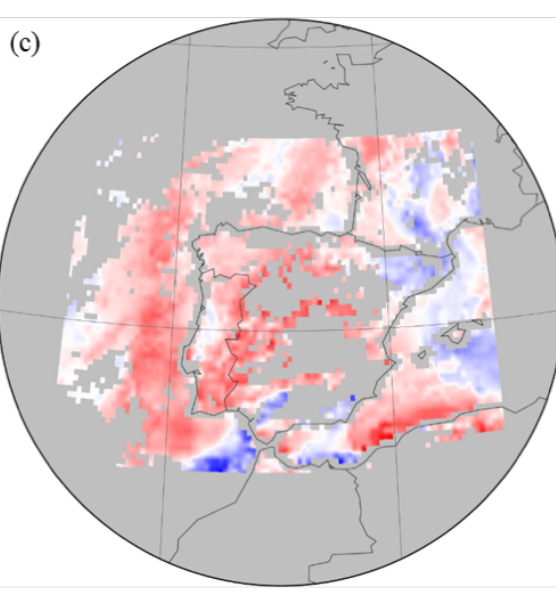

(d)

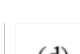

(d)

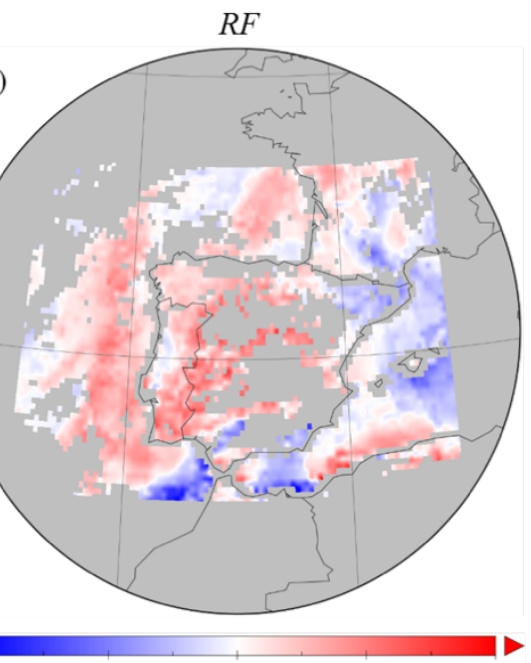

Correlation Coefficient
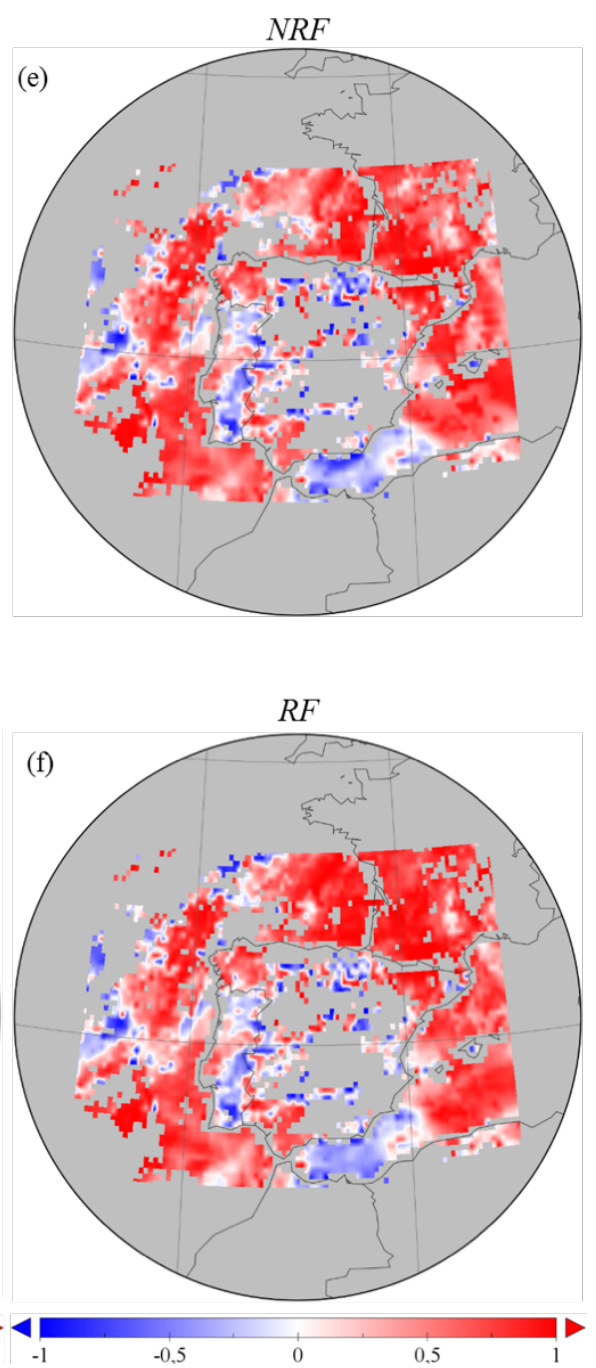

$\mathbb{-}_{-0,050}$ $-0,025$ 0,025 $0,050 \mid-0,30$ $-0.15$

Figure 1: Comparison of $\mathrm{AOD}_{550}$ model output vs. AOD 550 from Aqua-MODIS data for the dust episode. (a) AOD MODIS values. (b) Improvement of MAE due to the inclusion of RF (MAE in RF-NRF simulations). (c) and (d) MBE for NRF and RF simulations, respectively. (e) and (f) correlation coefficient for NRF and RF simulations. 


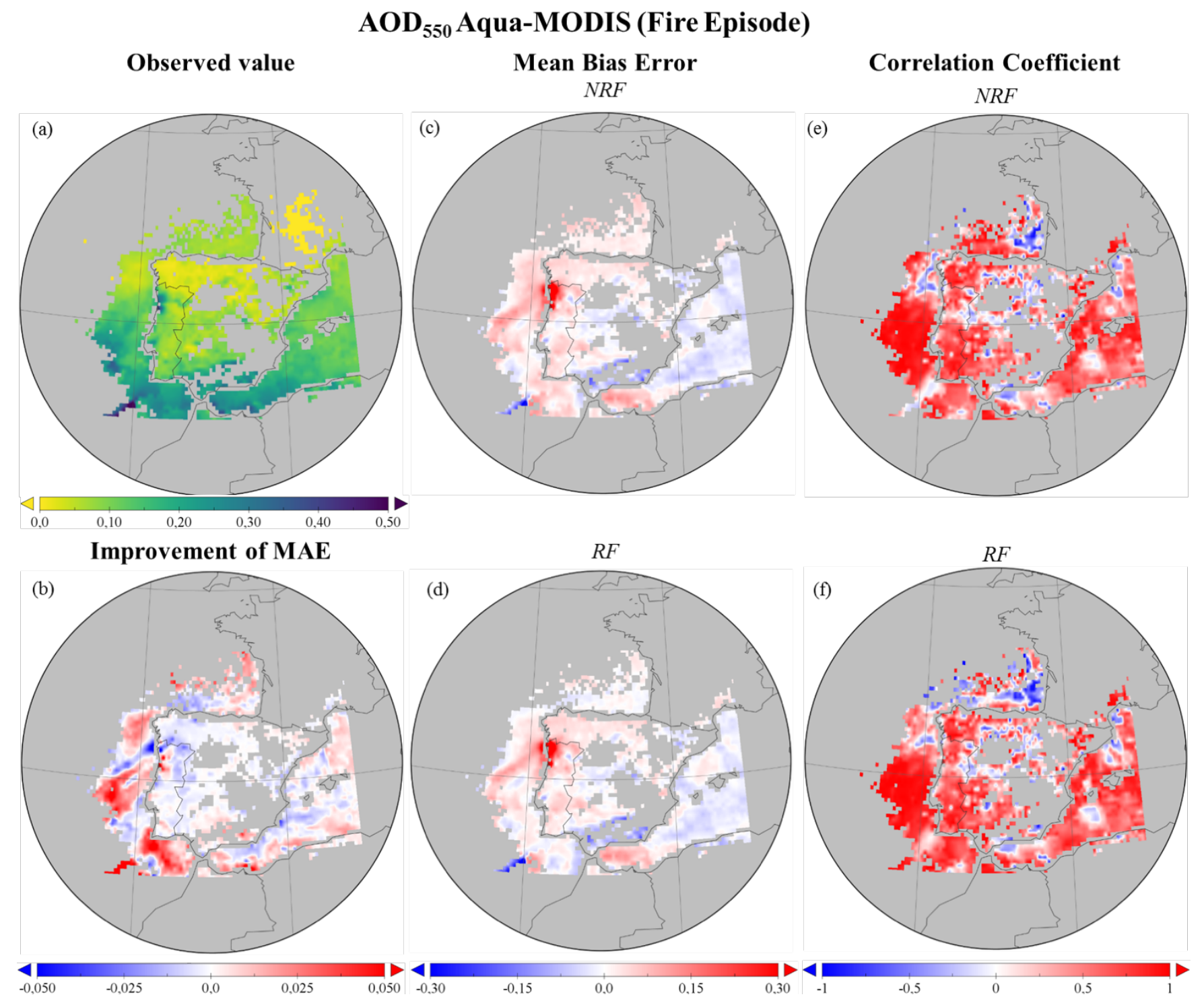

Figure 2: As Fig. 1 for the fires episode. 
$\mathrm{AE}_{550 / 860}$ Aqua-MODIS (Dust Episode)

Observed value

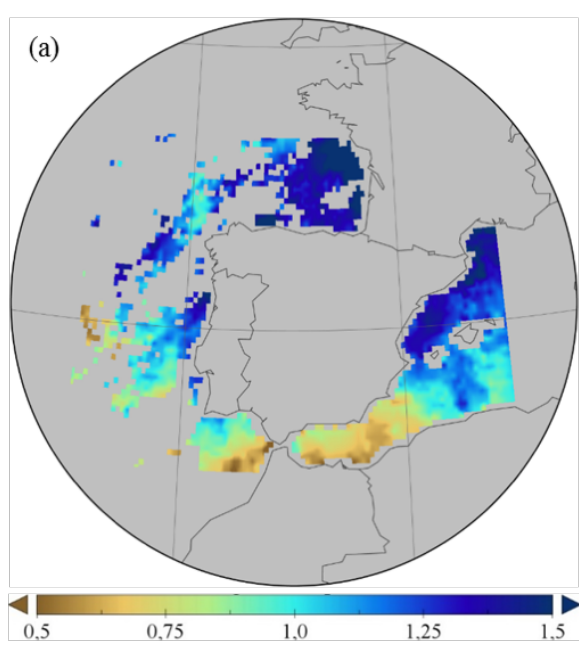

Improvement of MAE

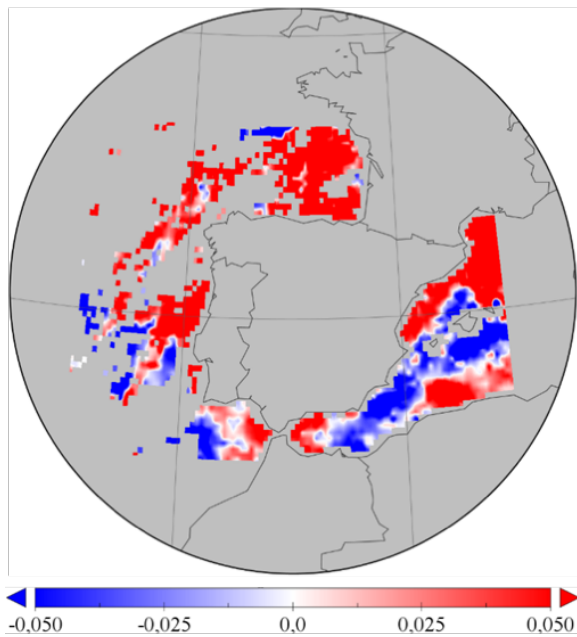

Mean Bias Error

$N R F$

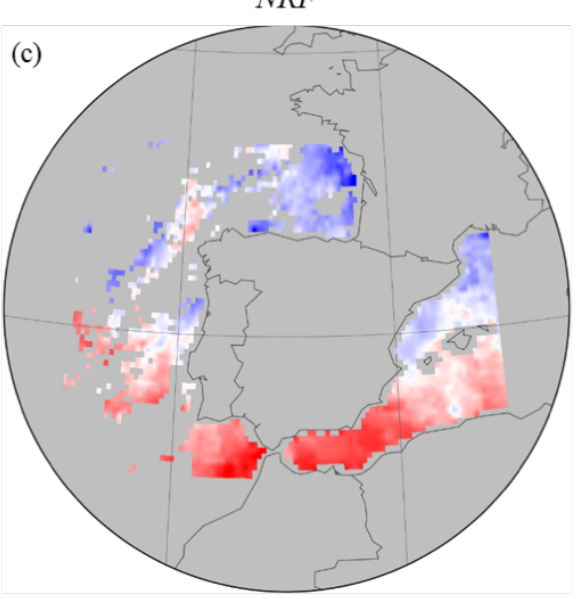

(c)

(1)
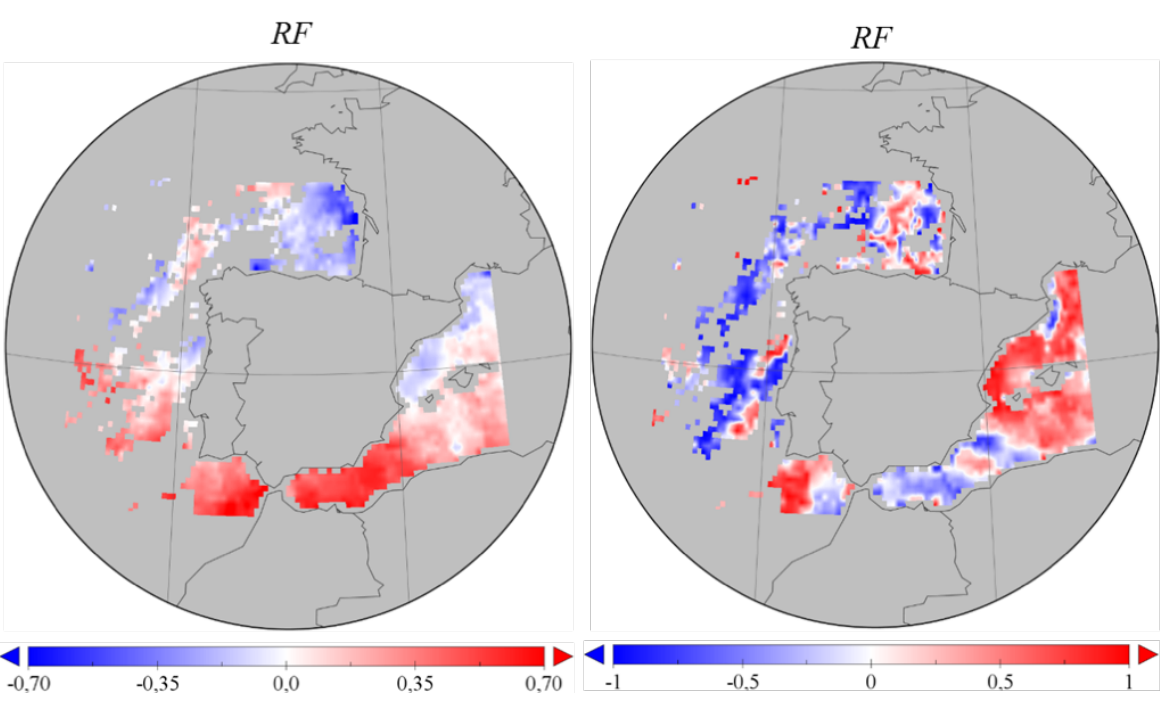

Figure 3: Comparison of $\mathrm{AE}_{550 / 86}$ model output vs. $\mathrm{AE}$ at same wavelength from Aqua-MODIS data for the dust episode. (a) $\mathrm{AE}$ MODIS values. (b) Improvement of MAE due to the inclusion of RF (MAE in RF-NRF simulations). (c) and (d) MBE for NRF and RF simulations, respectively. (e) and (f) Correlation coefficient for NRF and RF simulations. 
$\mathrm{AE}_{\text {550/860 }}$ Aqua-MODIS (Fire Episode)

Observed value

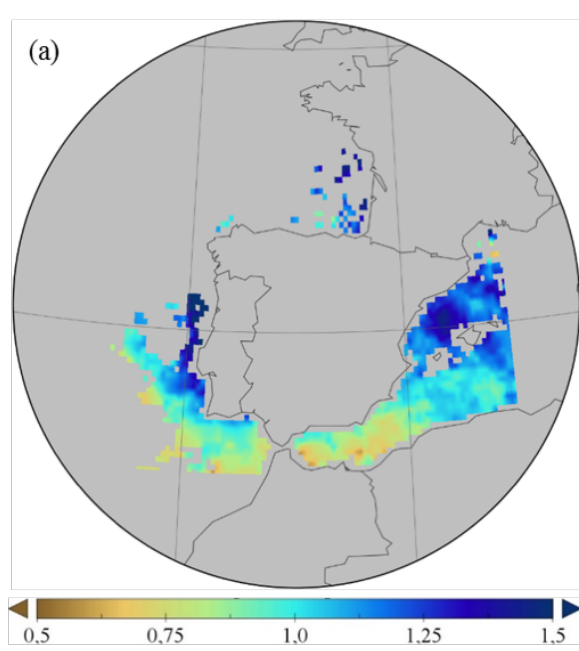

Improvement of MAE

(1)

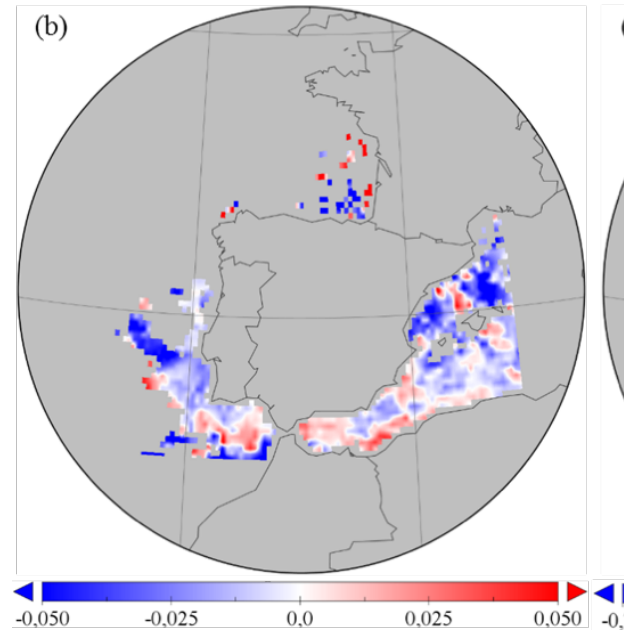

Figure 4: As Fig. 3 for the fires episode.

(c)
Mean Bias Error
Correlation Coefficient

$N R F$
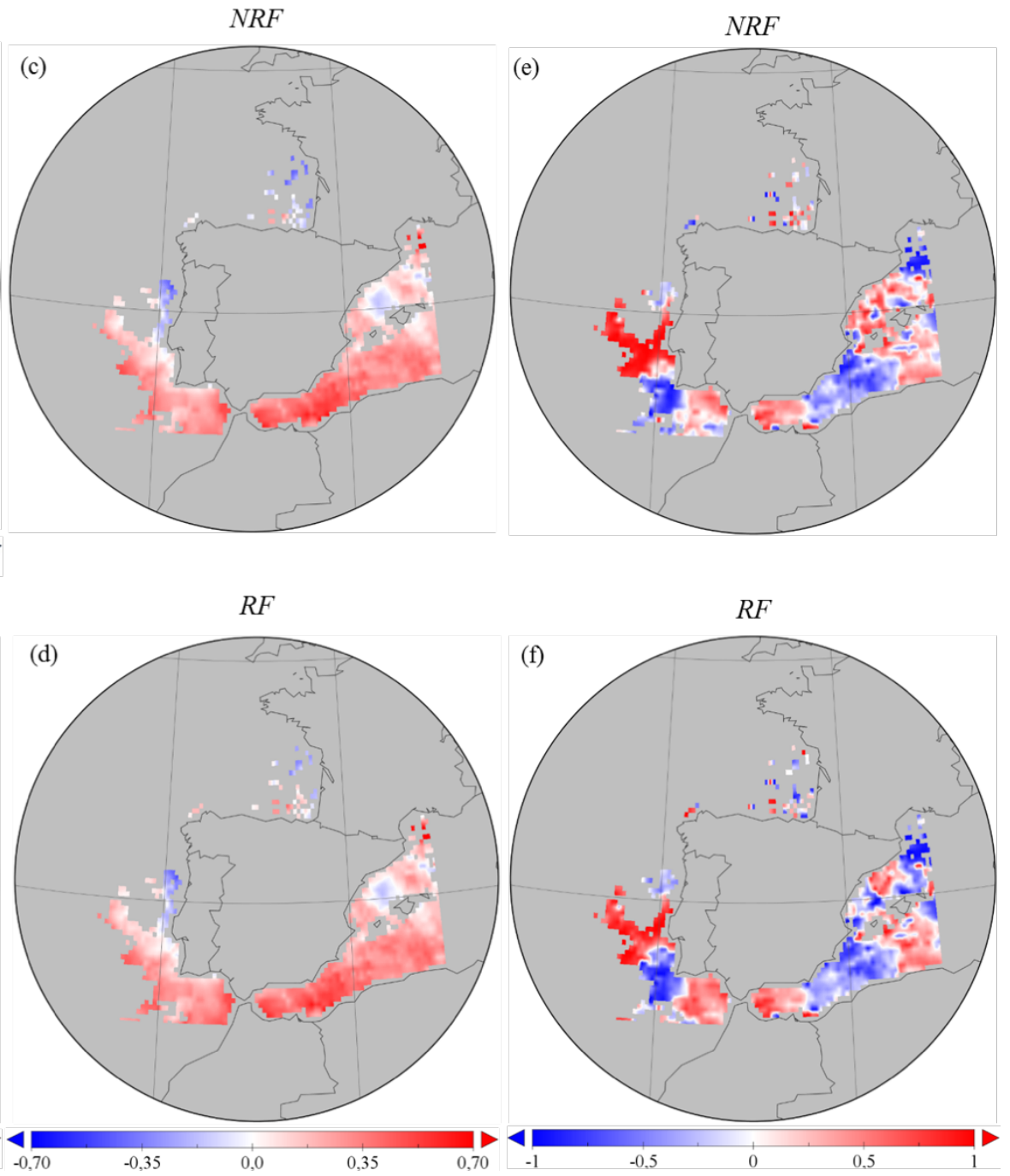

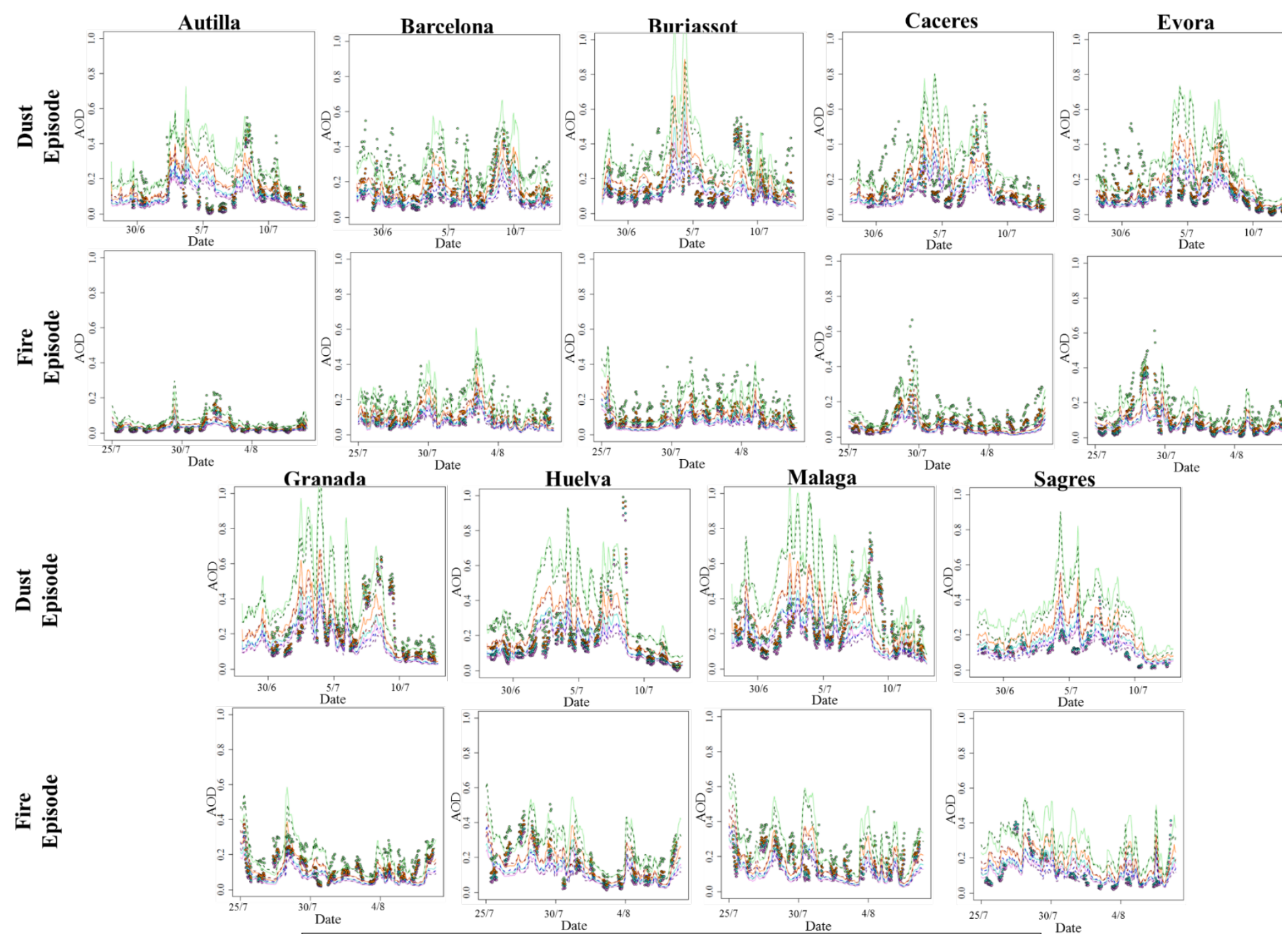

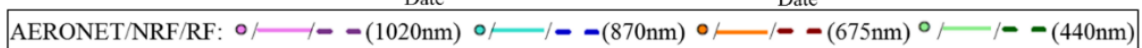

Figure 5: AERONET data (dots), NRF (line) and RF simulations (dashed line): AOD at different AERONET wavelengths. 

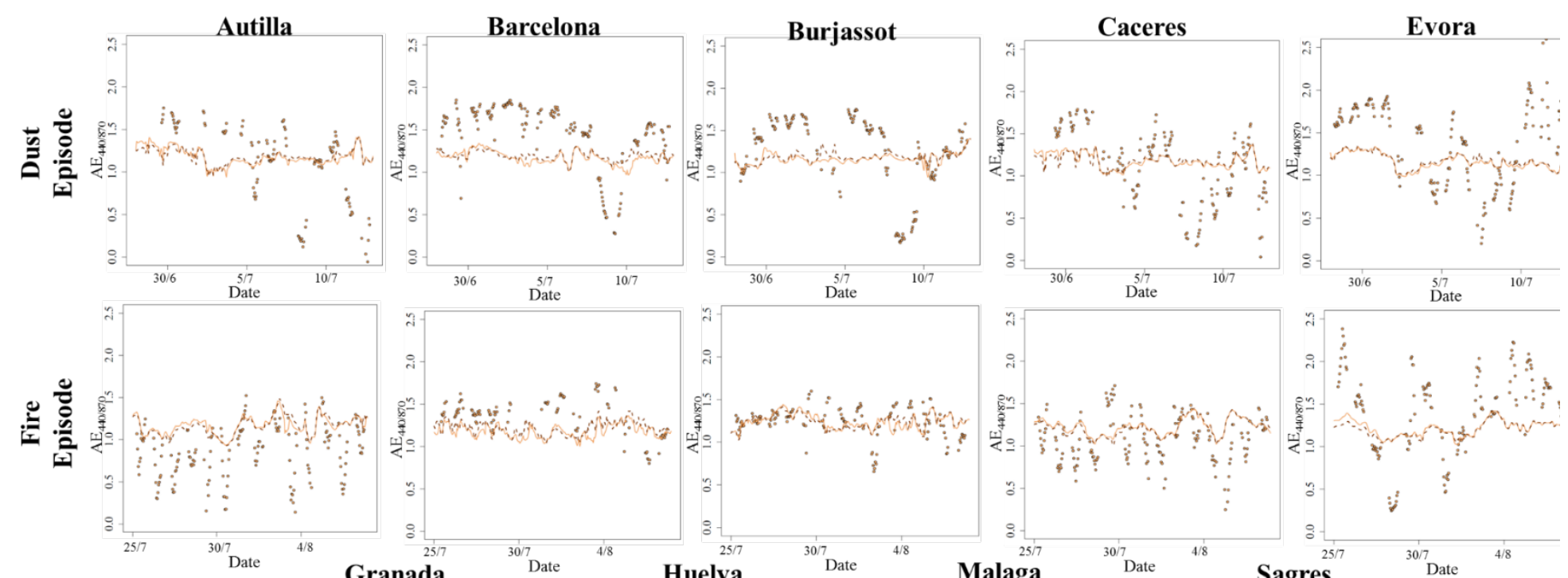

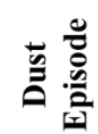
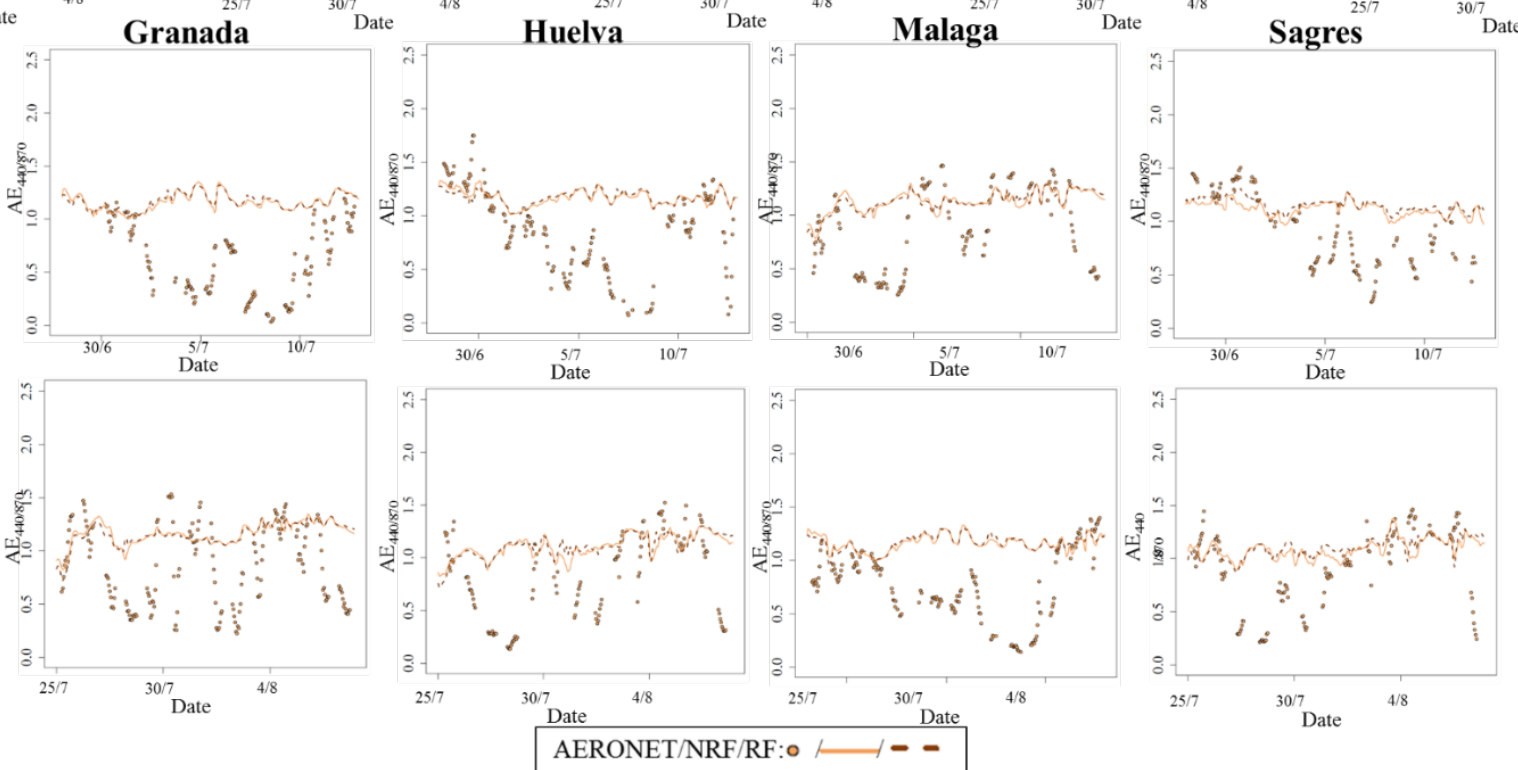

产葛

Figure 6: AERONET data (dots), NRF (line) and RF simulations (dashed line): $\mathbf{A E}_{440 / 870}$. 